\title{
Risk perception for HIV/AIDS infection among premarital sexually initiated youth in Nigeria
}

\author{
Blessing Uchenna Mberu, Ph.D* \\ *African Population and Health Research Center \\ P.O. Box 10787, 00100 GPO \\ Shelter Afrique Center, Longonot Road, Upper Hill \\ Nairobi, Kenya ${ }^{1}$ \\ bmberu@aphrc.org
}

\section{Abstract}

This paper examines perception of risk of HIV/AIDS infection among I,308 premarital sexually initiated youth aged 15-24, with data from the 1999 and 2003 Nigeria Demographic and Health Surveys. Building on the importance of the behavioral approach in a successful effort to limit HIVIAIDS transmission and evidence that subjective perception of one's own risk of infection is an important correlate of individual adoption of risk-reduction strategies, the study finds significant levels of discordance between risk perception and corresponding sexual behavior. The emanating challenge is identifying and understanding ways to accurately assess personalized and generalized risks, in order to achieve alignment of risk perception with actual sexual behavior. Following propositions that behavioral change in response to HIV/AIDS should in part be the consequence of a sense of personal vulnerability to infection, key interventions in Nigeria need to include an aggressive educational approach to address risk denial about HIV/AIDS emanating from misperceptions and rationalizations.

Keywords: Risk, perception, HIV/AIDS, premarital, sexual

\section{Résumé}

Cet article traite de la perception du risque d'infection par le VIH/SIDA auprès de 1308 jeunes âgés de 15 à 24 ans et ayant déjà eu une experience sexuelle prénuptiale. Les données utilisées proviennent des Enquêtes Démographiques et de Santé du Nigéria, conduites en 1999 et 2003. S'appuyant sur l'importance de l'approche comportementale dans la réussite des efforts pour limiter la transmission du VIH et la preuve que la perception subjective de son propre risque d'infection est un corrélat important de l'adoption individuelle des stratégies de réduction des risques, l'étude constate des niveaux significatifs de discordance entre la perception du risque et le comportement sexuel correspondant. Il en découle que le défi est didentifier et de comprendre les moyens d'évaluer avec précision les risques personnalisés et généralisés, afin de faire en sorte que la perception du risque corresponde au comportement sexuel réel. En suivant les propositions selon lesquelles le changement de comportement en réponse au $\mathrm{VIH} /$ SIDA devrait être en partie la conséquence d'un sentiment de vulnérabilité per-

I. Tel. office: $+254-20-2720400 /$, Cell: $+254-732544959$, Fax: $+254-20272380$ 
sonnelle à l'infection, les interventions clés au Nigeria nécessitent d'inclure une approche déducation aggressive pour traiter le déni du risque sur le VIH / SIDA émanant de perceptions erronées et de rationalisations.

Mots clés : Risqué, perception, vih/sida, premarital(e), sexuel(le).

\section{Introduction}

Subjective perception of one's own risk of sexually transmitted infection (STI) has been shown in theoretical and empirical literature as a prerequisite for or correlate of whether an individual adopts risk-reduction strategies (Kohler et al. 2007; Smith 2003; UNAIDS 1999). In sub-Saharan Africa, researchers have demonstrated significant association between individual correct assessment of risk and the prevalence of protective behaviors as condom use (Prata et al. 2006) and seeking of VCT services (Kibombo et al. 2007). Despite evidence of widespread knowledge about sexually transmitted infections in the region, particularly in the context of the HIV/AIDS epidemic, individual subjective perception of risk of STls have been found to vary substantially, ranging from those who perceive themselves at great risk to those who perceive no risk at all. A more problematic dimension of risk perception in the region is the finding that significant proportion of men and women who considered themselves at no risk or at small risk of contracting HIV was actually at moderate or high risk (Prata et al. 2006). In the context of significant premarital sexual activities, inaccurate perception of risk becomes even more problematic when sexually initiated and sexually active youth perceive themselves at no risk of STIs.

Following the prevailing low levels of contraception and protective meas- ures (Ministry of Health, Uganda and ORC Macro, 2006; Dann, 2009) and the consequent debilitating outcomes as HIV/AIDS, unwanted pregnancies, unsafe abortion, and high fertility rates among youth (Smith, 2000; Otoide et al. 200I; Arowujolu et al. 2002; IsiugoAbanihe, 2003; NPC and ORC/ MACRO, 2003; Aziken et al. 2003; AjaNwachuku, 2004; Bankole et al. 2006), the need for better understanding of the dynamics of young people's sexual engagement, in order to inform successful interventions remain undiminished.

In this paper, I examine risk perception for HIV/AIDS infection among Nigerian youth, who have initiated premarital sex and responded to the question on their perception of risk of HIV/ AIDS infection. The analysis seeks to specifically distinguish between the characteristics of youth who initiated premarital sex and yet perceive no risk of infections (the incidence of risk denial) relative to those who admit some level of risk of infection. The importance of the study is premised on evidence that understanding the determinants of individual perception of risk of infection is an essential step in the prevention of STls particularly HIV/ AIDS (Kohler et al. 2007). The particular focus on premarital sexually initiated youth is critical since inaccurate risk assessment among this group is a direct indicator of the current level of risk associated with premarital sexual engagement among sexually initiated 
youth. I examined data on I,308 youth who have initiated premarital sex at the time of survey and have no missing information on HIV risk perception and covariates considered for the study. Following the perspective that adolescent risky sexual behavior is a predictor of a pattern of other deviant involvements (French and Dishion, 2003), understanding perception of risk of an STI like HIV/AIDS can be useful in understanding perception of risks for related outcomes such as unwanted pregnancy, unsafe abortion and the consequences of other youth problem behaviors such as drug and substance abuse.

Nigeria's 140 million people are mostly young. The median age of the population is put at 17.4 years, over 45 percent are aged 0-14 and about 63 percent are less than 25 years of age. In the context of competing traditional values of family, parents and religion on one hand against powerful peer pressure and forces of modernization and globalization that equate sexuality with modern, educated, urbane lifestyles (Smith, 2000, 2003), premarital sexual relationships are increasingly common in contemporary Nigeria (Agha, 2009; Smith, 2000; 2004a; Meniru, 1996; Oronsaye \& Odiase, 1983). Young people in the country are increasingly linked to risky sexual behaviors such as casual sex and keeping of multiple partners, some of whom may include commercial sex workers (Isiugo-Abanihe, 2003; Arowujolu et al. 2002; Smith, 2000). These findings are consistent with the country's increasing HIV/AIDS prevalence rates between 1992 and 2001 (1.8 per cent in 1992 to 3.8 per cent in 1994, 4.5 per cent in 1996, 5.4 per cent in 1999 and 5.8 per cent in 200I) with most of the new cases found among the youth (Federal Ministry of Health, 200I). However, through concerted effort of the Nigerian Government, the prevalence rate has witnessed a decreasing trend in recent years (5.0 percent in 2003, 4.4 percent in 2005 and 3.1 percent in 2007) (UNAIDS, 2005; 2008a). Nevertheless, Nigeria still ranks third in terms of the number of people infected with HIV after India and South Africa, with 2.6 million people living with HIV/AIDS in 2007 (UNAIDS, 2008b). Moreover, the proportion of young people aged I5-24 who are HIV infected remain higher than the national prevalence at $4.33 \%$ (Federal Ministry of Health, 2005). This is compounded by high levels of unwanted pregnancies and clandestine abortions by untrained or poorly trained providers (Aja-Nwachuku, 2004; Aziken et al. 2003; Bankole et al. 2006; NPC and ORC/MACRO, 2003; Otoide et al. 200I). The depressing scenario underscores the enormity of challenge of protecting the next generation of Nigerians from the consequences of early and unprotected premarital sexual engagement. This in turn requires an updated understanding of factors that influence youth reproductive behaviors in the country.

There is a dearth of national level studies on youth reproductive behavior as most of the studies undertaken on the subject in the country are largely constrained by limited coverage. Some are based on data collected from youth in schools, leaving out non-school youth, who are estimated to constitute over 60 percent of the youth population (Slap et al. 2003; Amazigo et al. 
1997; Arowujolu et al. 2002). Other studies are limited to urban Nigeria leaving off the rural areas where an estimated $65 \%$ of the population live (Smith, 2004ab; Makinwa-Adebusoye, 1992; Feyisetan \& Pebley, 1989), and some are constrained by focus on evermarried women or unmarried female youth, entirely leaving out the male gender (Isiugo-Abainihe \& Oyediran, 2004; Ajuwon et al. 2002). Consequently, this study uses data from the 1999 and 2003 nationally representative Nigeria Demographic and Health Survey, with samples of school and nonschool men and women, aged 15-24, from all the regions of the country including rural and urban areas to specifically identify the predictive roles of individual, household and community factors in perception of risk of infection of HIV/AIDS among youth who have initiated premarital sexual relationships. The focus on this group of young people is strengthened by the need to study particular groups whose sexual behavior exposes them to real than imagined risks of sexually transmitted infections.

\section{Literature review and theoretical orientation}

This study on HIV/AIDS risk perception among Nigerian youth is premised on the postulations of individual and social behavior theories, that have generally provided insights into sexual risk behaviors and associated outcomes.

Individual behavior models highlight the roles of individual characteristics in controlling individual behavior. They generally focus on how individuals control their own behaviors and make reasoned decisions that impact those behaviors, with particular focus on psychological and cognitive factors believed to influence behavioral change (Smith, 2003). The Health Belief Model (HBM) is a dominant individual psychological model, which attempts to explain and predict health behaviors by focusing on the attitudes and beliefs of individuals (Rosenstock et al. 1994; Bandura, 1989). The model was developed in the 1950s as part of an effort by social psychologists in the United States Public Health Service to explain the lack of public participation in health screening and prevention programs. Over the years since its formulation, the HBM has been adapted to explore a variety of health and contraceptive behaviors, including sexual risk behaviors and the transmission of HIV/AIDS in diverse populations (Janz and Becker, 1984). The core postulate of the model is the assumption that an individual's characteristics, prior experiences and current surroundings shape his or her perceptions concerning the risks and severity of behavioral outcomes- such as contracting the AIDS virus through sexual conduct - and thereby influence behavior (Brockerhoff and Biddlecom, 1999).

One major limitation of individual characteristics models is the scant attention to broader contextual forces that may influence individual behavior. The models do not adequately incorporate social and cultural norms and peer influences on people's decisions regarding their health-related behaviors particularly sexual behavior, lending themselves to the potential bias of "individualistic fallacy", which occurs when population patterns of outcomes of interest are erroneously presumed to be explained only by individual-level 
characteristics (Krieger et al. 1997). Further, evaluations of interventions based on the HBM have shown consistent disappointing effects on risky behavior, giving strength to criticism that the individual is an inadequate unit of analysis (Auerbach et al. 1994).

The limitations of cognitive-behavioral, individual models in the study of risk behavior have been complemented by social behavior models that focused on social and community factors operating independently of individual characteristics (Smith, 2003). The overarching perspective across social models is the perspective that beyond individual personal and psychological characteristics, social relationships and structural factors constrain people's options for behavioral change. Consequently, social behavior models focus on the influences that derive from social relationships and the community of which the individual is a part as the basis for sexual behavior and key to behavioral change (UNAIDS 1999). Smith (2003) summarized the factors considered by social models to include social pressures, peer influences, cultural expectations, economic factors affecting available resources, legal and political structures, and political and religious ideologies that restrict individuals' options and the flow of information.

Building on these postulations, this analysis adopts a multi-factor perspective that simultaneously consider risk perception among Nigerian youth as an important dimension of the study of sexual and reproductive behavior of young people determined by a combination of individual characteristics and their particular social and cultural contexts - including peers, family, school, church, community, national and global environments.

\section{Data and methods}

\section{Data}

This study uses data from the 1999 and 2003 Nigeria Demographic and Health Surveys (NDHS), whose samples were designed to provide estimates of population and health indicators for urban and rural areas and all the regions of the country. Both surveys were each designed to select probability unbiased nationally representative samples of eligible respondents within all regular households in the entire country. A total of 1,308 young men and women aged 15-24 who initiated premarital sex and responded to the question on their perception of risk of HIV infection were drawn into the study.

Both surveys used household questionnaires to obtain information on housing characteristics, living facilities and household composition. Individual questionnaires for men and women provided information on current and previous places of residence, duration of stay in current residence, respondent's age, education, religion, ethnicity, status and nature of employment, reproductive behavior and intentions, knowledge and use of contraception, knowledge of and perception of risks for STIs, and other variables.

\subsection{Methods}

\subsubsection{Definition of variables}

The primary goal of the study is to identify the individual characteristics of youth aged 15-24 at the time the survey, who have initiated premarital sex and yet perceive themselves at no risk 
of sexually transmitted infections. The comparative group is those of the same age bracket who also initiated premarital sexual relations but admitted their risk of infection of HIV/AIDS. Male and female questionnaires used for the 1999 and 2003 surveys asked respondents about their perception of risk of sexually transmitted infection: Do you think your chances of getting AIDS are small, moderate, great, or no risk at all? The responses enabled a binary classification of those who perceived no risk at all relative to those who perceived some level of risks. Those who indicated that they already had AIDS were not included in the analysis.

To explore the multi-factor predictors of risk perception, empirical and theoretical literature reviewed inform the selection of other predictor variables. In particular, the study examined the relationships between risk perception and individual characteristics: migration status, current age, age at first intercourse, gender, educational attainment, and religious affiliation.

One important predictor of young people's premarital sexual behavior is migration status. Consistent with the individual models of human behavior is the perspective that the act of voluntary movement - often over long distances between radically different sociocultural environments and with uncertain consequences and social support networks at destinations - defines migrants, to a greater or lesser degree as innovators or risk-takers (Massey et al. 1994). This selectivity principle has led to distinctions between migrants and non-migrants, with migrants seen as predisposed towards heightened risk-taking behavior including riskier sexual behavior than others in their new social settings, owing to personal traits established before migration (Brockerhoff and Biddlecom, 1999). In this study, migration status is defined from a combination of questions on childhood place of residence before age 12 , current place of residence, duration of stay in current residence and type of previous and current places of residence (rural or urban; city, town or countryside). Without a direct question on migration status in any of the two rounds of the NDHS, responses to these questions are used to determine the lifetime migration status of young people: Rural and Urban Non-migrants, Rural-Rural Migrants, Rural-Urban Migrants, Urban-Urban Migrants and Urban-Rural Migrants. Non-migrants are young people whose childhood place of residence remains their current place of residence. Migrants are those whose current places of residence are outside their places of childhood residence prior to the survey.

The surveys provided information on age at survey in single years which was recoded into 5 age groups of two year gaps. Gender is coded 0 if male and $I$ if female. The surveys provided information on highest educational attainment of respondents, which for this analysis is recoded into four educational attainment categories: No education, primary education, secondary and higher education. Information on religious affiliation of respondents was recoded into four categories: Catholic, Protestant/Other Christians, Muslim and Traditional/Other. In examining the role of the nature/status of employment, the youth were classified on the basis of the nature of independence 
from parental supervision which each employment confers: formal employment, self/agricultural employment, and the unemployed. Youth in formal employment are most likely to be economically independent and spatially separated from parents and relatives when compared to others. Unemployed youth on the other hand are most likely to depend on parents and relatives for sustenance and therefore more likely to remain under their influences.

The association between household variables and perception of risk is examined using current living arrangements (household structure) and household socioeconomic status. The surveys provided information on the relationship between young people and the head of households. Those who are heads of households are defined as having transited into independent living outside the authority and supervision of their parents. They are compared to those who are living under their parents as children, or with relatives or a spouse. In determining household economic status, the 2003 Nigeria Demographic and Health Survey constructed wealth index and quintiles through principal components analysis of household possessions. However, the 1999 survey have no such index. Following this approach (see also Montgomery, et al. 2000; Gwatkins et al. 2000; Filmer and Pritchett, 1999; Mberu, 2006, 2007), a household wealth index is constructed for the pooled 1999 and 2003 data sets. The factor scores generated for all households are recoded into wealth quintiles.

The role of community-level variables in predicting perception of risk is examined through place of childhood residence before age 12 and ethnic origin. Place of childhood residence was provided in four response categories: "Capital, large city", "City", "Town", and "Countryside". The countryside was defined as rural following other studies in the region, and the complementary categories were defined as urban. To deal with the problem of multicollinearity, current place of residence was not included in the multivariate models. The surveys provided information on 112 ethnic groups in the country. To assess variations in youth perception of risk of HIV/AIDS among these diverse cultural groups, they were classified into six major cultural categories, approximating the nation's geopolitical zones and following the Nigerian Institute for Social and Economic Research's categorization (1997). The three main groups (Hausa-Fulani/Kanuri, Yoruba and Igbo), represent the core North, South West and South East cultural regions respectively. The Minority tribes of Central Nigeria and those of the Niger Delta were respectively grouped into two cultural zones. Finally the myriad of groups that could not fit into these five clear categories were grouped together as others. The final control variable included in the multivariate models is index of media exposure. The surveys asked whether respondents listen to radio every day, read newspaper and magazines once a week and watch television every week. Using the simple summation of frequency method, I for yes and 0 for no, I constructed two levels of exposure to the mass media. Data limitation prevents the inclusion of other variables such as condom use at first sex ${ }^{2}$ in this 
particular analysis.

\subsubsection{Statistical methods and models}

This study employs univariate (frequency tables), bivariate (cross-tabulations, chi-square tests of associations), and binary logistic multivariate techniques for the analyses of data. The binary logistic regression model developed for the multivariate analysis of the predictors of the perception of risk of HIV/AIDS infection is written as:

$\log \left(\mathrm{P}_{\mathrm{i}} /\left(\mathrm{I}-\mathrm{P}_{\mathrm{i}}\right)=\beta_{0}+\beta_{\mathrm{I}} \mathrm{X}_{\mathrm{I}}+\beta_{2} \mathrm{X}_{2}\right.$ $+\beta_{3} X_{3}+{ }_{4} X_{4} \ldots+\beta_{p} X_{p}+E_{1}$

where $P_{i}$ is the probability of any of the defined events of interest for an individual $i$ and ( $I-P$ is the compliment). $\beta_{0}$ is the base log odd of the reference categories of $X s$ and $\beta_{j}$ is the estimate of log odds of each outcome due to the net effect of a given category of the explanatory variables $X_{j .} E$ is the error term associated with regression. All reported binary logistic regression models were estimated using the STATA statistical package.

\subsubsection{Limitations of the study}

Pooling of data often poses drawbacks particularly in terms of compatibility of survey design and responses. However in this study, both surveys have compatible questionnaire designs and therefore comparable responses. A virtue of repeated surveys is that they can be pooled to increase sample size ${ }^{3}$ so long as the effect of the study variable is relatively invariant over the period (Firebaugh, 1997). The pooled surveys are conducted very close to each other; moreover the primary interest of the study is to identify the predictors of risk perception, rather than in drawing inferences about how these outcomes vary over time. Following the focus on a special group of young people the probability of an individual young person being covered in the two surveys is remotely infinitesimal.

One important limitation is that associated with limited migration data in the Demographic and Health Surveys. It is important to recognize that following how migration status was derived from a series of indirect questions, the migration categories derived may be sensitive to alternative definitions of migration status that could be derived from direct and more detailed data sets on migration histories. It is important to note that the migration variable defined represents lifetime migration status. There are possibilities of previous migration experiences but the limitation of data did not enable a clarification of this situation. However, since the subject of this study are young people, with likely very short migration histories, misclassification of origin among them should be low, as the likelihood of reclassification increases with time and the tendency is higher for long term migrants (Chattopadhyay et al. 2006).

Despite the limitations identified the national representativeness of the

2. The variable was not present in the 1999 survey, which provided most of the respondents that assessed their risks of HIV/AIDS infection.

3. Increasing the sampling size is very relevant in this study following the low response rate to the question on assessing risk perception among youth in the two surveys. 
data remains its invaluable strength, which enhances the generalizabilty of its findings to the country as a whole.

\section{Results of the study}

An overview of the characteristics of the study population

Out of the I, 308 Nigerian youth aged 15-24 all of which has had premarital sexual debut 44.7 perceived no risk of HIV/AIDS infection. This group, which fits a sexually high-risk youth group, is consistent with the disconnection found between what youth know about HIV/ AIDS and what they do to protect themselves.

Despite high levels of migration among Nigerian youth, about 50 percent of the youth are rural and urban non migrants, with the least of them involved in urban-rural and rural-rural migration streams. The gender composition is skewed in favor of women in the ratio of $3: 1$. This is consistent with the sampling procedure of the Demographic and Health Surveys, where a sub-sample of one-third of the households selected for the women interview were selected for the men's interview. This procedure has been criticized for generally collecting less information on reproductive behavior of men often with sample sizes too small to permit many useful analyses (NRCIM, 2005).

Table I Univariate characteristics of the study population

\begin{tabular}{lll}
\hline Variable & Frequency & Percentage \\
\hline Perception of HIV/AIDS risk & 724 & 55.4 \\
Some risk of infection & 584 & 44.7 \\
No risk of infection & & \\
Migration status & 236 & 18.0 \\
Urban-Urban migrants & 62 & 4.7 \\
Urban-Rural migrants & 232 & 17.7 \\
Rural-Urban migrants & 119 & 9.1 \\
Rural-Rural migrants & 240 & 18.4 \\
Urban non-migrants & 419 & 32.0 \\
Rural non-migrants & & \\
Gender & 937 & 71.6 \\
Female & 371 & 28.4 \\
Male & & \\
Current age & 103 & 7.9 \\
I5-16 & 256 & 19.6 \\
I7-18 & 354 & 27.1 \\
I9-20 & 296 & 22.6 \\
$21-22$ & 299 & 22.9 \\
$23-24$ & &
\end{tabular}


African Population Studies Vol 24, 3 (2010)

\section{Religion}

Muslims

Catholics

289

22. 1

Protestants/Other Christians

700

53.5

Traditional/Others

10

0.8

\section{Ethnic origin}

Hausa/Fulani/Kanuri 65

65

Igbo

304

23.2

Niger-Delta groups

270

20.6

Middle-Belt groups

11.6

Yoruba

23.9

Others

Childhood place of residence

Rural

532

40.7

Urban

776

59.3

Year of survey

1999

1,000

76.5

2003

308

23.6

\section{Education attained}

No education

75

5.7

Primary level education

259

19.8

Secondary education

854

65.3

Tertiary education

120

9.2

Type of employment

Unemployed $\quad 760$

58.1

Formal employment

433

33.1

Agriculture/Self employment

115

8.8

Living arrangements

Youth head of household

106

8.1

Youth as spouse of head

230

17.6

Youth as child of head

680

52

Youth as relative of head

292

22.3

Household wealth index

Poorest

233

17.8

Poor

236

18

Middle

204

15.6

Rich

336

25.7

Richest

299

22.9 
Index of media exposure

Low exposure

High exposure

On religion, 22.6 percent of the study sample are Muslims, 22.I and 53.5 percents are Catholics and Protestants respectively, while just one percent are traditionalists and other religious groups. Ethnic origin of the sample reflects the dominance of the Yoruba and the Igbo, but not the Hausa/Fulani/ Kanuri in the general population. Minorities of central and southern Nigeria make up about 36 percent of the sample.

The study population is composed of a significant high level of literacy with an impressive 65 percent having attained secondary education. That however contrasts with the low levels of higher educational attainment, which is consistent with observations that listed sub-Saharan Africa with the former Soviet Asia and South America, as world regions where percentage of tertiary education enrollments have dramatically declined in recent years (NCRIM, 2005). The largest proportion (58 percent) of the sample is unemployed, but among the employed, more are in formal than in agriculture or self employment. The few youth employed in the agricultural sector may not reflect the efficiency of the sector as in developed societies, where lower participation reflects better factor utilization, but instead may be an indicator of the unattractiveness of the agricultural sector for young adults, which among other factors engender migration out of rural origins to urban non-agricultural sectors (Mberu, 2005). In terms of living arrangements, 52 percent of the study sample live with their parents, 22
653

percent live with relatives. Of the remainder, 8.I percent and 17.6 percent live independently and with spouses respectively. The household wealth index is evenly distributed across the three lowest wealth categories, with higher proportions around the rich and richest categories. Finally there is an even distribution of youth with lower and higher exposure to the mass media.

\section{Perception of risk of sexually transmitted infection: descriptive analyses}

In assessing the individual characteristics of those who deny risks of infection relative to those who admitted their risks, Table 2 shows that rural-urban migrants relative to other migrant streams are most likely to deny the risk of infections.

Generally, youth with some level of education relative to those with no education, females compared to males, and Muslims than Christians, perceive themselves at no risk of HIV/AIDS infections. Similarly, youth who currently live with a spouse, in formal employment, those with highest media exposure and those from poorest households are most likely to indicate that they are at no risk of HIV infection despite premarital sexual initiation. Place of childhood residence prior to age 12 indicates a significant outcome, with urban residents more likely to perceive no risk of infection and an important bivariate outcome is the year of survey. While $58 \%$ of young people 
surveyed in 1999 perceived no risk of infection after premarital sexual initiation; all those surveyed in 2003 that assessed their risks, acknowledged some level of risk of infection. This may be an indicator of successful enlightenment campaigns over the period and/or the maturity of the HIV/AIDS epidemic to the extent that its ubiquity can no longer be denied. Finally, higher proportions of the Yoruba youth and those from the Niger-Delta perceive no risk of infection. While the bivariate associations identified are statistically significant, they are only suggestive as they may be likely biased by confounding variables. To account for potential bias, the independent association between risk perception and individual youth characteristics are refined in the multivariate logistic regression models, whose results are summarized in Table 3.

Table 2 Perception of risk of HIV/AIDS among premarital sexually initiated Nigerian youth $(\mathrm{N}=\mathrm{I}, 308)$

\begin{tabular}{lll}
\hline Variable & At some risk of infection & At no risk of infection \\
\hline Migration Status & \\
Urban-Urban migrants & 56.4 & 43.6 \\
Urban-Rural migrants & 69.3 & 30.7 \\
Rural-Urban migrants & 47.8 & 52.2 \\
Rural-Rural migrants & 58.0 & 42.0 \\
Urban non-migrants & 55.0 & 45.0 \\
Rural non-migrants & 56.3 & 43.7 \\
Gender*** & & \\
Female & 51.0 & 49.0 \\
Male & 66.3 & 33.7 \\
Current age & & \\
I5-I6 & 46.6 & 53.4 \\
I7-I8 & 54.3 & 45.7 \\
I9-20 & 59.0 & 41.0 \\
2I-22 & 55.1 & 44.9 \\
23-24 & 55.2 & 44.8 \\
Religion*** & & \\
Muslims & 46.9 & 53.1 \\
Catholics & 67.5 & 32.5 \\
Protestants/Other Christians & 53.9 & 46.1 \\
Traditional/Others & 70.0 & 30.0 \\
& &
\end{tabular}




\section{Ethnic origin***}

Hausa/Fulani/Kanuri

69.2

30.8

lgbo

70.4

29.6

Niger-Delta groups

50.4

49.6

Middle-Belt groups

55.3

44.7

Yoruba

35.6

64.4

Others

65.4

34.6

Childhood residence*

Rural

40.6

Urban

47.4

Year of survey***

1999

41.6

58.4

2003

100

00.0

\section{Education attained*}

No education

Primary level education

Secondary education

Tertiary education

Type of employment****

Unemployed

57.5

48.5

42.5

Formal employment

67.0

Agriculture/Self employment

Living arrangements**

Adolescent head of household

Adolescent as spouse of head

44.8

55.2

Adolescent as child of head

55.9

Adolescent as relative of head

Household wealth index**

Poorest

50.2

Poor

47.0

53.0

Middle

59.8

40.2

Rich

59.2

40.8

Richest

58.9

41.1

Index of media exposure***

Low exposure

70.2

29.2

High exposure

40.4 


\section{Perception of risk of sexually transmitted infections: multivariate analyses}

The results in Table 3 indicate that urban-rural migrants relative to rural non-migrants are consistently more likely to admit some risk of HIV infection in all models. For rural-urban migrants however, the outcome is in the opposite direction as they are significantly more likely to deny any risk of HIV/AIDS infection in Models I - 3. This positive association with risk denial remains in the full model (rural-urban migrants are $47 \%$ more likely than rural non-migrants to perceive no risk of infection) though the relationship was no longer statistically significant.

In all models, gender difference is significant, with females more likely to perceive no risk of infection. In the context of age asymmetry of sexual partners and transactional sex, together with the consequent female power dis- advantage in negotiating safer sexual practices such as the use of condoms (Luke, 2003), this outcome is potentially perilous, particularly if the result is a logical extension of the tendency of female youth to under-report their sexual activities. Indicating perception of some STI/HIV/AIDS infection risk may be counterproductive in maintaining a respectful image, which may be important in navigating societal expectations of a respectable young woman and the marriage market (Smith, 2003, 2004a). Youth in the older age categories are less likely to deny exposure to risk of HIV/AIDS infection relative to those who are younger. This outcome may be linked to the cumulative effect of exposure time, which may have afforded older youth opportunities to experience more sexual partnerships, increased likelihood of knowing some other infected persons, and adequate time to adequately assess their risks.

Table 3 Odds ratios predicting perception of no risk of HIV/AIDS infection among premarital sexually initiated Nigerian Youth $(\mathrm{N}=1,308)$

\begin{tabular}{|c|c|c|c|c|c|c|c|c|}
\hline \multirow[t]{2}{*}{ Variables } & \multicolumn{2}{|c|}{ Model I } & \multicolumn{2}{|c|}{ Model 2} & \multicolumn{2}{|c|}{ Model 3} & \multicolumn{2}{|c|}{ Model 4} \\
\hline & $\begin{array}{l}\text { Odds } \\
\text { ratio }\end{array}$ & SE & $\begin{array}{l}\text { Odds } \\
\text { ratio }\end{array}$ & SE & $\begin{array}{c}\text { Odds } \\
\text { ratio }\end{array}$ & SE & $\begin{array}{c}\text { Odds } \\
\text { ratio }\end{array}$ & SE \\
\hline \multicolumn{9}{|l|}{ Migration status } \\
\hline Rural non-migrants & 1.00 & - & 1.00 & - & 1.00 & - & 1.00 & - \\
\hline Urban-Urban migrants & 1.00 & .16 & 0.93 & .16 & 0.86 & .20 & 0.76 & .19 \\
\hline Urban-Rural migrants & $0.57^{\dagger}$ & .17 & $0.54 *$ & .16 & $0.55^{\dagger}$ & .18 & $0.53^{\dagger}$ & .19 \\
\hline Rural-Urban migrants & $\mathrm{I} .4 \mathrm{I}^{*}$ & .23 & $1.33^{\dagger}$ & .22 & $1.60 *$ & .38 & 1.47 & .37 \\
\hline Rural-Rural migrants & 0.93 & .20 & 0.88 & .19 & 0.93 & .21 & 0.85 & .21 \\
\hline Urban non-migrants & 1.05 & .17 & 1.12 & .18 & 1.07 & .23 & 0.95 & .22 \\
\hline \multicolumn{9}{|l|}{ Gender } \\
\hline Male & & & 1.00 & - & 1.00 & - & 1.00 & - \\
\hline Female & & & I.90*米米 & .25 & 2. 17 米米 & .30 & I.73**** & .28 \\
\hline \multicolumn{9}{|l|}{ Current age } \\
\hline $15-16$ & & & 1.00 & - & 1.00 & - & 1.00 & - \\
\hline $17-18$ & & & 0.75 & .18 & 0.73 & .18 & 0.75 & .2 \\
\hline
\end{tabular}


African Population Studies Vol 24, 3 (20l0)

19-20

$21-22$

23-24

\section{Religion}

Muslims

Catholics

Protestants/Other Christians

Traditional/Others

\section{Ethnic origin}

Hausa/Fulani/Kanuri

Igbo

Niger-Delta groups

Middle-Belt groups

Yoruba

Others

Childhood residence

Rural

Urban

Education Attained

No education

Primary level education

Secondary education

Tertiary education

Status/Type of employment

Unemployed

Formal employment

Agriculture/Self employment

Current Living arrangements

Adolescent as child of head

Adolescent head of household

Adolescent as spouse of head

Adolescent as relative of head

Household wealth index

Poorest

Poor

Middle

Rich

$\begin{array}{llllll}0.60^{*} & .14 & 0.57^{*} & .14 & 0.55^{*} & .14 \\ 0.74 & .17 & 0.70 & .17 & 0.63^{\dagger} & .17 \\ 0.73 & .17 & 0.70 & .17 & 0.59 * & .16\end{array}$

$1.00-1.00-$

$\begin{array}{llll}0.55 * & .12 & 0.61 * & .14\end{array}$

$\begin{array}{llll}0.68^{*} & .12 & 0.73^{\dagger} & .14\end{array}$

$\begin{array}{lllll}0.35 & .26 & 0.41 & .31\end{array}$

$1.00-1.00-$

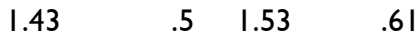

3.14*** I.I $2.86 *$ * $\quad$ I.I

$\begin{array}{llll}2.58 * * & .88 & 2.77 * * & \text { I.I }\end{array}$

5.65*** $\quad 1.8 \quad 4.27$ *** $\quad 1.6$

$\begin{array}{llll}\mathrm{I} .6 \mathrm{I} & .54 & \mathrm{l} .62 & .6 \mathrm{I}\end{array}$

$1.00-1.00$

$\begin{array}{llll}0.78 & .16 & 0.75 & .17\end{array}$

$\begin{array}{ll}1.00 & - \\ 1.19 & .4 \\ 0.86 & .28 \\ 1.00 & .39\end{array}$

1.00

I.37* $\quad .20$

0.83 
Richest

Index of media exposure

Low exposure

Higher exposure

LR chi2 (d. f)

$11.0(5)$

$4 I .4(10)$

$152.5(19)$

$274.2(32)$

No of observations $\mathbf{N}=1308$

$\dagger_{\mathrm{p}<.10,{ }^{*} \mathrm{p}<.05,{ }^{*} \mathrm{p}<.01,{ }^{*} * \mathrm{p}<.001}$

Relative to Muslims, Christians of all denominations are significantly more likely to admit some risk of sexually transmitted infections. Following previous findings that Christian youth are more likely to initiate premarital sex than Muslim youth (Mberu, 2008), this outcome may reflect an objective assessment of risk. However, it is important to take this perspective with caution as it is plausible that young people may more likely deny exposure to risk for sexually transmitted infections if such denial synchronizes with the normative expectations of their religious authorities. The need for caution is reinforced by findings that religious interpretation of HIV/AIDS in Nigeria frequently promotes a moral understanding of risk. Accordingly, the implicit immoral construction of HIV/AIDS infection among religious leaders and followers alike have been found to exacerbate the extent to which people must hide sexual relationships and deny all associated risks (Smith, 2004a).

Finally, while the lgbo exhibit no significant difference in perception of risks compared to the Hausa/Fulani/Kanuri, significant differences exist between the reference category and youth from other ethnic groups. Model 4 shows that Yoruba youth are 4.27 times as likely as the Hausa/Fulani/Kanuri to deny risk of exposure to sexually trans- mitted infections. Further, youth from the Niger-Delta are 2.86 times, and those from the Middle-Belt are 2.77 times as likely as the Hausa/Fulani/ Kanuri to perceive no risk of infection. These outcomes generally reflect the problematic disconnect between what people know about HIV/AIDS and what they actually do. The "state of denial" associated with each group, discordant with their actual premarital sexual behavior (Mberu, 2008), continues to underscore the high level of risk from STI/AIDS to which sexually active youth may be subjected in each group, particularly against the evidence of low levels of condom protection at sexual debut in Nigeria (15.8\%) and other countries in the region - $15.2 \%$ in Angola, 15\% in Tanzania, Malawi, and Ethiopia (Ndola et al. 2005; William et al. 1999; Zlidar et al. 2003).

Among the time-variant covariates, educational attainment is not significantly associated with risk perception in the full multivariate model. This outcome together with the bivariate result in Table I runs contrary to the expectation that higher education should expose youth to scientific knowledge that will rationally inform less risky sexual perception and choices, particularly if they have initiated premarital sex. Other results indicating the significant likelihood of denial of risk of HIV/AIDS 
infection include youth employed in the formal sector relative to the unemployed; and those with the highest exposure to the mass media relative to the least exposed. These counter-intuitive outcomes suggest that those who are more likely to know the routes of STI/AIDS infections are more likely to deny their vulnerability to the potential consequences of premarital sexual engagement. While it may mean that these groups are able to access protective services that hinder sexually transmitted infections and therefore perceive themselves at no risk of HIV/ AIDS, the low levels of condom use in the population generally and among youth in particular, provides little support for and a remote possibility of the validity of this perspective (Mberu, 2008).

Youth who initiated premarital intercourse and are living with a spouse at the time of the survey are $47 \%$ more likely to deny exposure to the risk of HIV/AIDS infection. Since the outcome here reflects perception at the time of the survey, the estimate may not have any direct association with premarital sexual risk behavior. However, it may speak directly to the belief of these youth that marriage protects sexual activities and a demonstration of faith in the fidelity of their sexual partners. It may also be part of building a respectful image, as admitting perception of some risk may be indicative of lack of trust in a spouse or a self report of infidelity. A recent study among youth aged 15-24 in South West Nigeria identified expectation of mutual fidelity as a determinant of risk perception. Adedimeji et al. (2007) found that youth who live with spouses attributed their perception of no risk of STls to having only one partner and trusting them. However, earlier studies point out that actual risk may be elevated for such women because of the sexual behavior of their partners as evidence has shown that male infidelity/ multiple partnerships is tolerated in most African societies (Caldwell et al. 1993), together with the context of high levels of sexual networking in Nigeria (Orubuloye et al. 1991; Messersmith et al. 2000).

Finally, Model 4 indicates significant variation in perception of risk among youth from households with varying levels of socioeconomic status. Those from the poorest households are more likely than those from the middle, rich and richest household categories to perceive no risk of sexually transmitted infection.

Understanding the mechanisms that fully drive these perceptions require further studies beyond this analysis. However, it is important to underscore the glaring discordance between risk perception and corresponding sexual behaviors identified in other studies. In particular, groups that are more likely to initiate premarital intercourse in previous studies are significantly more likely to deny any risk of sexually transmitted infections. This discordant outcome may be a key pointer that existing perception of risks are based on faulty premises, or are outright misperception. The emanating challenge for policies and programs therefore is identifying and understanding ways to accurately assess both personalized and generalized risks, in order to achieve alignment of risk perception with actual sexual behavior. 


\section{Discussion}

The importance of changes in sexual behavior to control the transmission of the HIV/AIDS epidemic and the relationship between how men and women come to perceive their risk of infection and how they come to formulate what they consider to be acceptable and effective strategies of prevention have been underscored by researchers in SSA (Kohler et al. 2007; Akwara et al. 2003). This paper examines risk perception of HIV/AIDS infection among Nigerian youth who had initiated premarital sexual relationships before the survey. The results indicate that $44.7 \%$ of sexually initiated youth perceive themselves as having no risk contracting HIV/AIDS. The findings are consistent with evidence that knowledge and perceptions are not generally translated to protective sexual engagement among Nigerian youth (Adedimeji et al. 2007; Smith, 2003, 2004a).

The multivariate analysis presents different dimensions of risk denial which, are discordant with actual youth sexual behavior. In particular, ruralurban migrants, who have the highest propensity to initiate early premarital sex, are also more likely to deny risk of HIV/AIDS infection. This discordance is also found among youth in formal employment relative to the unemployed, the Yoruba, Middle-Belt, Igbo and Niger-Delta youth relative to those of the Hausa/Fulani/Kanuri.

Understanding discordance between perception and behavior has engaged public health and social science researchers, and HIV/AIDS literature has identified significant insights. In a study of migrant lgbo youth, Smith (2003) linked the disparity between behavior and perception of risk to "conception of risk in ethical and moral terms and the complex intertwining of collectively-shared moralities with individual assessments of ethics of personal behavior." More elaborately, Smith's research reveals that young Nigerian migrants do not perceive significant personal risk of HIV infection because they construct the risk of AIDS in ethical and moral terms, projecting immorality and danger onto imaginary others. Thus young people interpret the epidemic without internalizing their own risks (Smith, 2003). In another study in South West Nigeria, Adedimeji et al (2007) suggested that so long as sexual relationships do not occur within institutionalized prostitution, risks are not only rationalized away but severely underestimated.

For young people living with spouses, their perception of no risk of STIs, which may indicate confidence in the faithfulness of their partners, becomes problematic for behavior change and control of infection, if their partners did not maintain sexual fidelity, which is likely, in the context of high levels of sexual networking among men and women in Nigeria.

\section{Conclusion}

The findings from this study suggest that risk perception of sexually transmitted infections among Nigerian youth may be flowing from at least two distinct routes. On the one hand is the perception that emanates from objective assessment of risks. This relates to young people whose risk perception is congruent with their premarital sexual behavior. This group has initiated premarital sex and subsequently perceives 
some risk of contracting HIV/AIDS. On the other hand, there are perceptions that fit the problematic discordant model, emanating perhaps from youth rationalizations and outright denials of risk despite manifest risky sexual engagement.

Against the backdrop of inaccurate assessment of risk for men and women, and the importance of the behavioral approach in a successful effort to limit HIV/AIDS transmission (Ndola et al. 2006), the results of this analysis provides an important nationally relevant evidence-base for interventions that will enhance young people's ability to correctly assess their risks relative to their sexual behaviour.

Following propositions of rationalistic theories of human behavior that behavioral change in response to HIV/ AIDS should in part be the consequence of a sense of personal vulnerability to infection (Toroitich-Ruto, 200I), key interventions in Nigeria need to include an aggressive educational approach that enlighten young people on common misperceptions about HIV/AIDS including their levels of vulnerabilities to infections.

\section{References}

Adedimeji, A.A., Omololu, F.O. and Odutolu, O. 2007. "HIV Risk Perception and Constraints to Protective Behaviour among Young Slum Dwellers in Ibadan, Nigeria." Journal of Health, Population and Nutrition 25(2): I 46- 157.

Agha, S. 2009. "Changes in the Timing of Sexual Initiation Among Young Muslim and Christian Women in Nigeria." Arch Sex Behav 38:899908.
Aja-Nwachuku, I. 2004. "Abortion among Non-School Youth in Nigeria." Paper presented at the 2004 Annual Meeting of the Population Association of America, Boston, Massachussets, U.S.A. April I-3.

Ajuwon, A.J., W. McFarland, E.S. Hudes, Adedapo, T. Okikiolu, and P.Lurie. 2002. "HIV risk-related behavior, sexual coercion, and implications for prevention strategies among female apprentice tailors in Ibadan, Nigeria." AIDS and Behavior 6(3): 229-235.

Akwara, P. A., Nyovani, J.M. and Hinde, A. 2003. "Perception of Risk of HIV/ AIDS and Sexual Behaviour in Kenya." Journal of Biosocial Science 35:3:385-4II.

Amazigo, U., Silva, N., Kaufman, J., and Obikeze, D. 1997. "Sexual Activity and Contraceptive Knowledge and Use among In-School Adolescents in Nigeria." International Family Planning Perspectives 23(I): 28-33.

Arowujolu, A.O., llesanmi, A.O., Roberts, O.A., Okunola, M.A. 2002. "Sexuality, contraceptive choice, and AIDS awareness among Nigeria undergraduates." African journal of Reproductive Health 6: 60-70.

Auerbach, J.D., Wypijewska, and K.H. Brodie (eds). 1994. AIDS and Behavior: An Integrated Approach. Washington DC: National Academy Press.

Aziken, M.E., P.I. Okonta and A.B. Ande. 2003. "Knowledge and Perceptions of Emergency Contraception Among Female Nigerian Undergraduates." International Family Planning Perspectives 29(2): 84-87.

Bandura, A. 1989. "Perceived self- 
efficacy in the exercise of control over AIDS infection." In V.M. Mayes, G.W. Albee and S.F. Schneider (Eds), Primary Prevention of AIDS: Psychological Approaches (pp. 12814I. London: Sage Publications.

Bankole, A., B. Oye-Adeniran, S. Singh, I.F. Adewole, D. Wulf, and R. Hussain. 2006. Unwanted Pregnancy and Induced Abortion in Nigeria: Causes and Consequences. Guttmacher Institute.

Brockerhoff, M. and Biddlecom, A. 1999. "Migration, Sexual Behavior and Risks of HIV in Kenya." International Migration Review, 33(4): 833-856.

Caldwell, J.C. and Caldwell, P. 1993. "The nature and limits of the subSaharan AIDS epidemic: Evidence from Geographic and other patterns." Population and Development Review 19: 817-848.

Chattopadhyay, A., M. J. White and C. Debpuur. 2006. "Migrant fertility in Ghana: Selection versus adaptation and disruption as causal mechanisms." Population Studies 60(2): I-I5.

Dann, G. 2009. Sexual behavior and Contraceptive use among youth in West Africa. Washington, DC: Population Reference Bureau

Federal Ministry of Health. 200I. A Technical Report on the 200I National HIV/Syphilis Sentinel Survey among Pregnant Women Attending Antenatal Clinics in Nigeria. Abuja: Department of Public Health, National AIDS/STDs Control Programme, Federal Ministry of Health.

Federal Ministry of Health. 2005. ANC Sentinel Survey. Abuja, Nigeria:
Federal Ministry of Health.

Feyisetan, B. and Pebley, A.R. 1989. "Premarital sexuality in Urban Nigeria." Studies in Family Planning 20 (6): 343-354.

Filmer D. and Pritchett, L. 1999. "The effects of Household Wealth on Educational Attainment: Evidence From 35 Countries." Population and Development Review 25(I): 85-I 20.

Firebaugh, G. 1997. "Analyzing repeated surveys." Sage University Paper Series on Quantitative Applications in the Social Sciences, No. 07-II5. Thousand Oaks, California: Sage Publications.

French, D.C. and Dishion, T.J. 2003. "Predictors of Early Initiation of Sexual Intercourse among High-Risk Adolescents." The Journal of early Adolescence 23(3):295-315.

Gwatkin, D.R., S. Rustein, K. Johnson, R.P. Pande, and A.Wagstaff. 2000. Socioeconomic Differences in Health, Nutrition, and Population in Kenya. Washington, DC: HNP/Poverty Thematic Group, The World Bank.

Isiugo-Abanihe, U.C. 2003. Male Role and Responsibility in Fertility and Reproductive Health in Nigeria. Lagos: Ababa Press Ltd.

Isiugo-Abanihe, U.C. and Oyediran, K.A. 2004. "Household Socioeconomic Status and Sexual Behaviour among Nigerian Female Youth." African Population Studies I9(I): 8I-98.

Janz, N.K. and Becker, M.H. 1984. "The Health Belief Model: A Decade Later." Health Education Quarterly I I:I-47.

Kibombo R., Neema, S. and Ahmed, F. 2007. "Perceptions of risk to HIV Infection among Adolescents in 
Uganda: Are they Related to Sexual Behaviour?" African Journal of Reproductive Health I I(3): I68-I8I.

Kohler, H-P., Behram, J.R., and Watkins, S.C. 2007. "Social networks and HIV/AIDS risk perceptions." Demography 44(I): I-33.

Krieger, N., D.R. Williams, and N.E. Moss. 1997. "Measuring Social Class in Us Public Health Research: Concepts, Methodologies, and Guidelines." Annual Rev Public Health 18: 341-378.

Luke, N. 2003. "Age and Economic Asymmetries in the Sexual Relationships of Adolescent Girls in sub-Saharan Africa." Studies in Family Planning 34(2): 67-86.

Makinwa-Adebusoye, P. 1992. "Sexual Behaviour, Reproductive Knowledge and Contraceptive Use among Urban Youth in Nigeria." International Family Planning Perspectives I8(2): 66 - 70.

Massey D. S.; J. Arango; G. Hugo; A.Kouaouci; A. Pellegrino; J.E. Taylor. 1994. "An Evaluation of International Migration Theory: The North American Experience." Population and Development Review 20(4):699-75I.

Mberu, B.U. 2008. Internal Migration and Premarital Reproductive Behavior Among Adolescents in Nigeria. Doctoral Dissertation, Department of Sociology, Brown University, Providence, USA.

Mberu, B.U. 2007. "Household Structure and Living Conditions in Nigeria."

Journal of Marriage and the Family 69: 5।3-527.

Mberu, B.U. 2006. "Internal Migration and Household Living Conditions in

\section{Ethiopia."}

Demographic Research 14(2I): 509-540.

Mberu, B.U. 2005. "Who moves and who stays? Rural out-migration in Nigeria." Journal of Population Research 22(2): |4|-|6|.

Meniru, G. I. 1996. "Premarital conception in married couples: The Nigerian lgbo experience." West African Journal of Medicine 15: 177180.

Messersmith, L.J., T.T. Kane, A.I. Odebiyi, and A.A. Adewuyi. 2000. "Who is at risk?

Men's STD experience and condom use in Southwest Nigeria." Studies in Family Planning 3I (3): 203-2I6.

Ministry of Health,Uganda and ORC Macro. 2006. Uganda HIV/AIDS Sero- behavioural Survey 2004-2005. Calverton, Maryland: Ministry of Health and ORC Macro.

Montgomery, M., M. Gragnolati, K. Burke, and E. Paredes. 2000. "Measuring Living Standards with Proxy Variables." Demography 37(2): I55-I74.

National Population Commission and ORC/Macro. 2003. Nigeria Demographic and Health Survey, 2003.Calverton, Maryland: National Population Commission and ORC/ Macro

Ndola, P., L. Morris, E. Mazive, F. Validnia and M. Stehr. 2006. "Relationship between HIV Risk Perception and Condom Use: Evidence from Population-Based Survey in Mozambique." International Family Planning Perspectives 32(4): 193-200.

Ndola, P., F. Vahidnia and A. Fraser. 2005. "Gender and Relationship Differences in Condom Use Among 
15-24 Years Olds in Angola." International Family Planning Perspectives 31(4): 192-199.

NRCIM (National Research Council and Institute of Medicine). 2005. Growing Up Global: The Changing Transitions To Adulthood In Developing Countries. Lloyd, C.B. (Editor). Washington, DC: The National Academies Press.

Oronsaye, A. U., and Odiase, G. I. 1983. "Attitudes toward abortion and contraception among Nigerian secondary school girls." International Journal of Gynecology and Obstetrics 21: 423-426.

Orubuloye, I. O., J.C.Caldwell, and P. Caldwell 199I. "Sexual networking in the Ekiti District of Nigeria." Studies in Family Planning 22 (2): 6I73.

Otoide, V.O., F. Orosanye, and F. Okonofua. 200I. "Why Nigerian adolescents seek abortion rather than contraception: Evidence from focus-group discussions." International Family Planning Perspectives 27(2): 77-8I

Rosenstock, I., Strecher, V., and Becker, M. 1994. "The Health Belief Model and HIV risk behavior change." In R.J. DiClemente, and J.L. Peterson (Eds), Preventing AIDS: Theories and Methods of Behavioral Interventions (pp.5-24). New York: Plenum Press.

Slap, G.B., Lucy Lot, C.A.Daniyam, T.M. zink and P.A. Succop. 2003. "Sexual Behavior of Adolescents in Nigeria: Cross Sectional Survey of Secondary Schools Students." BMJ 326: 15-18.

Smith, D.J. 2000. "'These girls today na war-o': premarital sexuality and modern identity in southeastern Nigeria." Africa Today 47(3/4): 98120.
Smith, D.J. 2003. "Imagining HIV/AIDS: Morality and perceptions of personal risk in Nigeria in Nigeria." Medical Anthropology 22(4): 343-372.

Smith, D.J. 2004a. "Premarital sex, Procreation, and HIV Risk in Nigeria." Studies in Family Planning 35(4): 223-235.

Smith, D.J. 2004b. "Youth, sin, sex in Nigeria: Christianity and HIV/AIDSrelated beliefs and behavior among rural-urban migrants." Culture, Health and Sexuality 6(5): 425-437.

Smith, K.P. 2003. "Why Are They Worried? Concern About AIDS in Rural Malawi." Demographic Research Special Collection I(9):279-3 I7. Available online at http://www.demographic-research.org/ special///9.

Toroitich-Ruto, C. 200I. "The Effect of HIV/AIDS on Sexual Behavior of Young People in Kenya." African Population Studies 12: 2. 39-50.

United Nations. 2004. Levels and trends of contraceptive use as assessed in 2002. United Nations. Dept. of Economic and Social Affairs. Population Division

UNAIDS. 1999. "Sexual behavioral change for HIV: Where have the theories taken us?" UNAIDS. Geneva.

UNAIDS. 2005. NIGERIA UNGASS REPORT FOR 2005. http:// data.unaids.org/pub/Report/2006/ 2006_country_progress_report_nigeri a_pdf (Accessed 31/3/2010).

UNAIDS. (2008a. NIGERIA UNGASS REPORT 2007. http://data.unaids.org/ pub/Report/2008/

nigeria_2008_country_progress_repor $t \_$df (Accessed 3l/3/20I0).

UNAIDS. 2008b. 2008 Report on the 
global AIDS epidemic. http:// www.unaids.org/en/KnowledgeCentre/ HIVData/GlobalReport/2008/

(Accessed 3I/3/20I0)

William, K.A., and C.S. Alexander 1999. "Determinants of Condom Use to prevent HIV Infection among Youth in Ghana." Journal of Adolescent Health 24: 63-72.

Zlidar, V.M. et al. 2003. "New survey findings: The reproductive revolution continues." Population Reports Series M, No 17. 